\title{
A APRENDIZAGEM ATIVA NO ENSINO DA DISCIPLINA DE PROJETO DE ARQUITETURA NA PUCPR, CURITIBA
}

\author{
EL APRENDISAJE ACTIVO EM LA ENSEÑANZA DE LA DISCIPLNA DE PROYECTO DE \\ ARQUITECTURA EM LA PUCPR, CURITIBA
}

THE ACTIVE LEARNING IN ARCHITECTURAL DESIGN IN PUCPR, CURITIBA

\section{ZUCCHERELLI, MOARA}

Mestre, Professora Adjunta da Pontifícia Universidade Católica do Paraná, moara.zuccherelli@pucpr.br

\section{RESUMO}

O presente artigo relata uma experiência didática realizada na disciplina de Projeto de Arquitetura IV, no terceiro ano do curso de Arquitetura e Urbanismo da Pontifícia Universidade Católica do Paraná - PUCPR, em Curitiba, durante o segundo semestre de 2018. 0 objetivo foi propor novas abordagens e procedimentos na disciplina com a utilização de Análise de Referências como ferramenta de grande importância no ensino-aprendizagem de projeto e, para tanto, utilizar estratégias de Metodologia Ativa - neste caso, Sala de Aula Invertida e Estudo de Caso - tendência que promove a motivação e o engajamento dos estudantes em uma aprendizagem mais efetiva. A metodologia adotada para o desenvolvimento deste estudo foi o redesenho da disciplina, com a montagem de um plano de ensino que assegurasse estratégias para a aprendizagem ativa e que apresentasse, de forma clara e objetiva, os resultados de aprendizagem, as habilidades e as competências esperadas. As mudanças foram aplicadas na disciplina e os resultados foram observados, registrados e analisados para possíveis ajustes ou reformulação futura. A experiência proporcionou levantar pontos positivos e pontos que precisam de atenção contínua na aplicação dos diferentes modelos de ensino. Este estudo pretende contribuir para a promoção de melhorias no ensino da disciplina de projeto de arquitetura.

PALAVRAS-CHAVE: ensino; projeto de arquitetura; aprendizagem ativa.

\section{RESUMEN}

El presente artículo relata un experimento didáctico realizado en la disciplina de Proyecto de Arquitectura IV, en el tercero año del curso de Arquitectura y Urbanismo de la Pontificia Universidad Católica de Paraná - PUCPR, en Curitiba, durante el segundo semestre de 2018. El objetivo fue proponer nuevos enfoques y procedimientos en la disciplina - la utilización de Análisis de Referencias como herramienta de gran importancia en la enseñanza de proyecto - y, para ello, utilizar estrategias de Metodología Activa - en este caso, Sala de Clase Invertida y Estudio de Caso -, tendencia que promueve la motivación y el compromiso de los estudiantes en un aprendizaje más efectivo. La metodología adoptada para el desarrollo de este estudio fue el rediseño de la disciplina, con el montaje de un plan de enseñanza que asegure estrategias para el aprendizaje activo y que presentara, de forma clara y objetiva, los resultados de aprendizaje, las habilidades y las competencias esperadas. Los cambios fueron aplicados en la disciplina y los resultados fueron observados, registrados y analizados para posible ajuste o reformulación futura. La experiencia proporcionó levantar puntos positivos y puntos que necesitan atención continua en la aplicación de los diferentes modelos de enseñanza. Este estudio pretende contribuir a la promoción de mejoras en la enseñanza de la disciplina de proyecto de arquitectura.

PALABRAS CLAVES: enseñanza; proyecto de arquitectura; aprendizaje activo.

\section{ABSTRACT}

The present article reports a didactic experiment carried out in the discipline of Project of Architecture $I V$, in the third year of the Architecture and Urbanism course of the Pontifical Catholic University of Paraná - PUCPR, in Curitiba, during the second semester of 2018. The objective was to propose new approaches and procedures in the discipline - the use of Reference Analysis as a tool of great importance in teaching and to do so, use Active Methodology strategies - in this case, Flipped Classroom and Case Study -, a tendency that promotes students' motivation and engagement in a more effective learning process. The methodology adopted for the development of this study was the redesign of the discipline, with the assembling of a teaching plan that ensure strategies for active learning and that presented, in a clear and objective way, the learning outcomes, the skills and the expected competences. The changes were applied in the discipline and the results were observed, recorded and analyzed for possible adjustment or future reformulation. The experience has provided positive points and points that need continuous attention in the application of the different teaching models. This study intends to contribute to the promotion of improvements in the teaching of architecture project.

KEYWORDS: teaching; architecture project; active learning. 


\section{INTRODUÇÃO}

Presente nos cursos de graduação em Arquitetura e Urbanismo no Brasil, a disciplina Projeto de Arquitetura ${ }^{1}$ é essencialmente prática e abrange parte significativa do aprendizado na área, uma vez que é nela que se exercita a prática projetual em diferentes níveis de complexidade. É também a disciplina que em geral concentra a maior carga horária dos cursos e é considerada a "espinha dorsal" da formação do profissional arquiteto e urbanista.

Apesar de sua enorme importância, o ensino de projeto, como é praticado em grande parte dos cursos do país, tem sido apontado, há muito tempo, como um problema ${ }^{2}$ e é contundente no meio acadêmico a constatação de que esta disciplina carece de mudanças, pesquisa e inovação:

Os problemas relacionados ao ensino da disciplina de Projeto continuam basicamente os mesmos há décadas, e, apesar de diagnosticados, ainda não foram resolvidos convenientemente. Além das antigas questões, encontram-se os novos desafios relacionados às conquistas tecnológicas e às rápidas transformações da sociedade, exigindo do profissional arquiteto um perfil cada vez mais flexível (RUFINONI, 2002).

Somado aos problemas específicos da formação do arquiteto e urbanista, com um mercado de trabalho cada vez mais exigente e complexo, ressaltam-se as atuais e constantes mudanças no perfil do profissional e da atuação dos indivíduos na sociedade. Com a popularização da internet e a grande gama de informações que ela traz, a sala de aula se torna, mais do que nunca, o lugar do debate, da reflexão e do crescimento intelectual. É consenso no meio acadêmico que o atual modelo de ensino, praticado na maior parte das instituições de ensino brasileiras, tem se mostrado pouco eficiente e este cenário demanda mudanças urgentes.

Na busca por estratégias pedagógicas inovadoras, com novas práticas metodológicas, surge a aprendizagem ativa, praticamente um "caminho sem volta", que visa promover a formação de um profissional apto a aprender e a pesquisar de forma continuada e autônoma. Para implantá-la é necessário mudar o foco do trabalho pedagógico centrado no docente - antes no papel do transmissor do conhecimento, agora de mediador no processo de construção do conhecimento, responsável por oferecer oportunidades para que a aprendizagem aconteça - e transferi-lo para o estudante - antes em atitude passiva, receptiva e reprodutora, atuando como espectadores, sem maior preocupação com a crítica e reflexão (BEHRENS, 2011) - agora com papel ativo e reflexivo, responsável e capaz de atualizar continuamente seus conhecimentos.

O docente, ao invés de ditar paradigmas ou criar receitas de projeto, deve incitar o aluno à investigação, à pesquisa e à experimentação, fazendo-o percorrer vários caminhos que permitirão novas reflexões, em um contínuo processo de aprendizagem, vivência projetual e, principalmente amadurecimento pessoal (RUFINONI, 2002).

Neste contexto, fica clara a necessidade de uma imediata e urgente reavaliação da maneira como se tem praticado o ensino de projeto nas universidades brasileiras, propor um novo desenho da disciplina e a adoção de uma pedagogia voltada para a formação acadêmica integral dos futuros arquitetos.

Foi neste cenário de grandes inquietações que surgiu a oportunidade de propor mudanças na condução da disciplina de Projeto de Arquitetura IV ${ }^{3}$, do $3^{\circ}$ ano $\left(6^{\circ}\right.$. período; as disciplinas são semestrais) do curso de Arquitetura e Urbanismo da Pontifícia Universidade Católica do Paraná - PUCPR, em Curitiba. Esta iniciativa é parte de ações relacionadas à melhoria do ensino, desenvolvidas por esta universidade nos últimos 4 anos. Além de proporcionar diversas oficinas de formação e atualização ao corpo docente, voltadas à implantação de novas práticas pedagógicas, o CrEAre - Centro de Ensino e Aprendizagem da PUCPR (criado em 2015 para apoiar as ações relacionadas à inovação no ensino da graduação) buscou uma parceria com a FINEP Financiadora de Estudos e Projetos, com o objetivo de gerar novas condições para promover a Aprendizagem Ativa.

A disciplina, objeto desta pesquisa, participou do projeto piloto, lançado em 2017 e iniciado em 2018, através de edital aberto às escolas da universidade (SPRICIGO; MANFFRA; SAROYAN, 2017), e desenvolvido durante três semestres letivos consecutivos. Durante este período ela foi totalmente reestruturada para se 
utilizar de novas estratégias de ensino. A metodologia foi aplicada, analisada e registrada e o presente artigo apresenta os resultados desta experiência.

\section{CONTEXTUALIZAÇÃO}

Nos últimos 50 anos, parece haver uma conduta já "consagrada" na forma como a disciplina de Projeto se desenvolve na maioria dos cursos de Arquitetura e Urbanismo das instituições de ensino brasileiras: os professores, ou os Projetos Pedagógicos, definem os "temas" de projetos de arquitetura (edifícios de diferentes usos como, por exemplo, edifício que abriga o uso de escola, igreja, museu, entre outros) a serem desenvolvidos; fornecem algumas informações como o terreno onde será realizado o projeto do edifício (localização, medidas, topografia, etc.), o programa de necessidades (a relação dos ambientes que o edifício deve comportar), os prazos e o material gráfico para as entregas das etapas do projeto. Ao longo da disciplina procedem às "assessorias", como é chamado o acompanhamento individual no qual os professores conversam com cada aluno a respeito de seus projetos e fazem sucessivos ajustes nos estudos propostos. E é, de fato, o que ocorre nestas disciplinas de Projeto: os estudantes recebem o "tema" e, de imediato, sem mais informações e/ou principalmente, reflexões, iniciam seus desenhos e passam pelas assessorias, onde o professor faz sucessivos ajustes nos estudos apresentados sendo comum, inclusive, perceber alunos tentando desenvolver as ideias esboçadas pelos professores, ao contrário de ensaiar suas próprias.

Na experiência como professora de projeto nos últimos 14 anos, pode-se afirmar que muitas vezes esses trabalhos resultam em apenas desenhos, ou seja, "projetos vazios", sem significado, que objetivam apenas uma composição harmônica (em planta) e a utilização de materiais de acabamento inovadores e atuais, distantes do que se entende por um projeto de arquitetura, em que tantos outros fatores devem ser levados em consideração. Isto é ainda mais evidente quando os estudantes apresentam seus projetos, pois frequentemente não há justificativa consistente sobre as escolhas feitas ou um entendimento mais abrangente do que o edifício projetado irá significar para o proprietário, os usuários, a vizinhança ou para a cidade.

Através do método do "aprender fazendo", muitos professores acreditam estar ensinando a projetar, mas não percebem que as informações dadas em sala de aula referem-se ao edifício que será projetado e não ao objetivo da disciplina, o ensino-aprendizagem de projeto. De certa forma, esta metodologia de ensino passa, indiretamente, a impressão de que os estudantes já deveriam saber projetar - inspiração, talento ou intuição nata? (SILVA, 2006) - e que, cada novo projeto, a "complexidade" que os "temas" vão ganhando ao longo dos anos do curso, traz apenas um novo "desafio" a vencer. Este procedimento acaba por acarretar uma visão distorcida e extremamente "simplificada" do significado de projeto de arquitetura e da arquitetura em si.

É fato que nos cursos de Arquitetura e Urbanismo o aprendizado se dá na própria prática de projetos, mas acredita-se que seja através da repetição de um procedimento - o processo de projeto - e pelo acúmulo de conhecimentos que isto pode acarretar. Na concepção de Alfonso Martinez, arquiteto e então professor da Universidade de Belgrano, em Buenos Aires, Argentina, "o projeto de arquitetura se configura em conhecimento arquitetônico aplicado, significando que em seu desenvolvimento constata-se 'o saber, transformando-o em fazer"' (MARTINEZ, 2000). Portanto,

(...) Nesta nova ambiência, buscam-se conceitos e métodos que embasem, e sobretudo legitimem, a prática e o ensino de projeto, pois não há dúvidas de que num projeto desenvolvido no contexto de uma escola de arquitetura, o que está em jogo não é a construção de uma obra, e sim, a construção de um estudante, futuro projetista ou seja, aprender a fazer projeto e fazer projeto são coisas diferentes (CORDIVIOLA, 2001. Grifo do autor).

Ou seja, a escolha de uma "metodologia de projetação", conceituada como "uma ordem de procedimentos capaz de alimentar a mente do projetista de diferentes estímulos para a realização do trabalho criativo" (NEVES, 1998) é uma opção que destitui formas pessoais de abordar o ensino de projeto.

Para a experiência desenvolvida na disciplina de Projeto IV, propuseram-se mudanças estruturais na disciplina e buscaram-se estratégias diferenciadas de ensino. O incentivo para a empreitada veio da aprovação, por meio de seleção interna da universidade, do "Projeto Piloto de Inovação no Ensino" proposto 
pela autora deste texto e um dos responsáveis pela disciplina. Para o primeiro semestre 2018, o edital previa a participação da professora em várias oficinas de atualização docente, oferecidas pelo CreARe. Nessas oficinas a disciplina foi sendo revisada e redesenhada, culminando na construção de um plano de ensino que assegurasse o emprego de estratégias de aprendizagem ativa. No semestre seguinte, essas mudanças foram colocadas em prática, ou seja, estas inovações foram aplicadas em sala de aula. A terceira etapa foi o compromisso assumido pela professora de escrever um artigo, divulgando os resultados alcançados, tarefa que resultou neste trabalho.

O plano de ensino, com plano de aulas detalhadas, foi organizado de forma a explicitar as competências e os resultados de aprendizagem pretendidos na disciplina, a sequência e o tipo das atividades a serem desenvolvidas, as metodologias ativas a serem utilizadas, a apresentação, com clareza e objetividade, dos critérios de avaliação (peso, tipo de avaliação - formativa e/ou somativa -, etc.), datas e/ou prazos, entre outros.

A aplicação da experiência foi acompanhada por observação sistemática de cada aula, em relação à motivação e ao envolvimento dos estudantes na participação das atividades propostas, conversas "informais", fotografias e questionários aplicados para coleta das impressões e reações dos alunos. Este material foi registrado e organizado num "Diário de Bordo", espaço de reflexão e de avaliação da efetividade das atividades desenvolvidas e das metodologias ativas utilizadas. Através do resultado dos trabalhos entregues pelos estudantes foi possível realizar uma análise criteriosa dos resultados de aprendizagem e indicadores e desempenho esperados.

\section{$A$ aprendizagem ativa}

$\mathrm{Na}$ aprendizagem ativa, o sujeito é o centro do processo; o foco está na aprendizagem e não no ensino; ela deve tratar de situações de conhecimento, de habilidades e de competências, colocando o estudante o como agente do processo e conscientizando-o do seu papel na sociedade. Nela, o processo de ensinoaprendizagem deve ter como "elemento principal a motivação com o intuito de gerar o engajamento dos alunos no processo de aprendizagem, levando-os a assumir a responsabilidade pela sua aprendizagem e desenvolvimento e assumir o protagonismo estudantil” (CAMARGO e DAROS, 2018, p.06).

As metodologias ativas apresentam dinâmica própria, uma vez que valorizam a construção do conhecimento, e dependem muito das interações dos estudantes com as instâncias envolvidas em seu aprendizado. Por isso, é importante ressaltar que, ao escolher as estratégias mais apropriadas, o professor não pode perder de vista os resultados de aprendizagem que pretende alcançar, direcionando e orientando todo o processo para esse fim.

Na literatura, há uma variedade de abordagens e definições, com o "passo a passo" de aplicação de cada metodologia. Durante as oficinas do Projeto Piloto de Inovação no Ensino, os docentes participantes conheceram e praticaram várias delas e tomaram conhecimento das especificidades e particularidades nas suas aplicações e no preparo de material prévio às aulas.

Este estudo não tem a pretensão de tratar teoricamente de cada uma e sim de apresentar a análise da aplicação das metodologias escolhidas, Sala de Aula Invertida (flipped classroom) e Estudo de Caso, no projeto piloto desenvolvido na disciplina de Projeto de Arquitetura IV, quais adaptações foram feitas e quais resultados apresentaram. Será, portanto, utilizada, mais adiante, uma definição "simplificada", tipo quick reference, disponibilizada nas oficinas de formação e atualização docente ofertadas pelo CreARe, PUCPR.

Estas metodologias não foram desenvolvidas seguindo o passo a passo descrito na literatura. Foram adaptadas ao contexto específico da atividade prática de atelier de projeto.

\section{Relato da experiência}

A disciplina de Projeto de Arquitetura IV tem a duração de um semestre letivo, com carga horária total de 120 horas, distribuídas em dois encontros semanais de 4 horas/aula cada. A turma era do turno da tarde, com 32 alunos e dois professores. O projeto a ser desenvolvido neste período do curso, conforme deliberações do Colegiado do Curso, é um edifício para uma Escola de Ensino Fundamental em Curitiba. Em vez de lançar o tema de projeto aos alunos, selecionar o terreno e iniciar o desenvolvimento, decidiu-se tentar uma abordagem totalmente diferente em relação à forma como o semestre se desenvolveria: ficou estabelecido que em sete, das dezesseis ou dezessete semanas de aula do semestre, os estudantes desenvolveriam atividades que fundamentassem e embasassem o início do projeto com responsabilidade e assertividade. 
A proposta baseou-se na NBR 13532 - "Elaboração de projetos de edificações - Arquitetura" da Associação Brasileira de Normas Técnicas (1995) que aponta, como etapas de execução da atividade técnica do projeto de arquitetura:
a) levantamento de dados para arquitetura;
b) programa de necessidades de arquitetura;
c) estudo de viabilidade de arquitetura;
d) estudo preliminar de arquitetura;
e) anteprojeto de arquitetura ou de pré-execução;
f) projeto legal de arquitetura;
g) projeto básico de arquitetura (opcional);
h) projeto para execução de arquitetura.

Mesmo constando na norma brasileira, o que se percebe é que, de forma geral, os estudantes iniciam seus projetos a partir da etapa "d" (estudo preliminar de arquitetura), não havendo obrigatoriedade, cobrança ou esclarecimento, de boa parte dos professores, a respeito da importância e necessidade das etapas anteriores. Essa "despreocupação" dos docentes talvez seja decorrente do fato de que um bom profissional arquiteto não precisa necessariamente ser um bom professor de projeto e até por este motivo torna-se fundamental que os docentes com experiência prática de projeto, reflitam mais sobre suas próprias práticas profissionais.

A necessidade de enfocar as etapas anteriores à etapa "d" da NBR, no desenvolvimento de projetos de arquitetura", baseia-se na hipótese de que ao se "envolver" e conhecer mais profundamente o objeto a ser projetado, os projetistas adquirem mais segurança e tendem a imprimir maior "significado" ao ato de projetar. A partir dessa premissa, a reflexão sobre as etapas "a" (levantamento de dados), "b" (programa de necessidades) e "c" (estudo de viabilidade), que fundamentam as etapas posteriores de projeto, passaram a compor as aulas iniciais da disciplina.

Foram propostos 10 passos ${ }^{5}$ a serem desenvolvidos um a um e em sequência, acreditando que "a passagem entre fases sucessivas em uma proposta projetual se apoia em um juízo realizado sobre a anterior" (PIÑON, 2006, p.48). Foram, também, planejadas atividades específicas para cada passo, variadas dinâmicas em sala de aula e o uso de diferentes metodologias ativas, de forma a envolver o aluno na compreensão de cada passo, incitando uma constante reflexão da prática projetual:

\begin{abstract}
Ainda que seja apresentado como uma série linear de passos, o processo de projeto costuma ser mais como um ciclo interativo no qual uma sequência de análises cuidadosas, sínteses e avaliações de informações disponíveis, insights e soluções possíveis são repetidas até que se alcance um ajuste adequado entre o que existe e o que se deseja (CHING, 2006, p.47).
\end{abstract}

O primeiro desafio era explicar aos estudantes, de forma clara e objetiva, por que desenvolver esses passos e a sua real importância para o início do projeto, pois percebe-se que constantemente que os alunos se "atiram" em cumprir as tarefas solicitadas sem realmente entender que elas fazem parte do processo de aprendizagem. Acreditava-se que se os estudantes compreendessem perfeitamente o processo, se envolveriam com mais responsabilidade. O segundo desafio era conseguir avaliar se estas atividades - os 10 passos - estariam, de fato, aumentando o conhecimento de forma a projetarem com mais segurança. $\mathrm{O}$ terceiro desafio era avaliar se as metodologias ativas escolhidas para o desenvolvimento das atividades teriam o alcance planejado.

Para maximizar as chances de sucesso, propôs-se que os encontros ocorressem da seguinte maneira: no início de cada aula, seria apresentado um passo, através de aulas expositivas com breve abordagem do tópico a ser desenvolvido, seu significado no processo de projetação, como desenvolvê-lo, como trabalhar com as informações coletadas, apresentando exemplos reais para ilustrar e, na sequência, se prosseguiria para as aulas práticas, ou seja, depois de apresentado o conteúdo de cada tópico ele deveria ser, de imediato e em sala de aula, testado e praticado pelos estudantes. Somente após trabalhar com esses 10 passos, os estudantes iniciariam o Estudo Preliminar (etapa "d", da norma brasileira).

A experiência foi muito gratificante tanto para os alunos como para os professores. O que se relatará a seguir é o que se praticou apenas no $2^{\circ}$ passo, dos dez propostos, chamado Análise de Referências. 
A Análise de Referências, método considerado de grande importância para a aprendizagem de projeto de arquitetura, consiste em desenvolver a análise técnica de um projeto já executado e utilizar este conhecimento como referência para o projeto que se vai desenvolver

O objetivo de desenvolver tal análise, além de ampliar o repertório arquitetônico do estudante é, como apresentado por Unwin (2013, p.01), "oferecer o início de uma estrutura para a compreensão analítica de obras de arquitetura já que a compreensão analítica das obras de arquitetura deve ser vista como base e estímulo para a atividade criativa que é projetar". O autor coloca que

\begin{abstract}
A arquitetura é uma aventura mais bem explorada pelo desafio de praticá-la. Porém, como em qualquer outra disciplina criativa, a aventura da arquitetura pode se inspirar na análise daquilo que outros fizeram e, por meio desta análise, tentar entender as maneiras que eles encontraram para alcançar os desafios. (...) Como arquiteto considero esse exercício útil (...). Acredito, simplesmente, que podemos desenvolver a capacidade de praticar a arquitetura se estudarmos como ela foi praticada por outros (UNWIN, 2013, p.03, grifo nosso).
\end{abstract}

Inserir esta atividade nas disciplinas de projeto dos cursos de arquitetura e urbanismo não é novidade e muitos professores, em diversas escolas, a praticam regularmente. Na PUCPR, praticamente todas as disciplinas de projeto incluem a atividade como "conteúdo" do semestre contudo, infelizmente, não se consegue perceber o real alcance dos objetivos pretendidos com ela, no ensino-aprendizagem de projeto. Acredita-se que o problema possa estar na forma como a atividade é desenvolvida. Em um rápido levantamento realizado entre os professores das disciplinas de projeto desta universidade, foram identificadas diferentes estratégias utilizadas nas diversas turmas do curso, algumas mais efetivas, outras com resultados menos expressivos. Seguem algumas das situações encontradas:

(i) O aluno seleciona o projeto de referência: o aluno escolhe projetos (em sites da internet, livros, revistas, em folders de venda, etc.), que não trazem resultados concretos em relação aos conteúdos que se pretende desenvolver. Mesmo quando os professores fornecem os critérios para a escolha dos projetos, percebe-se que os alunos acabam selecionando projetos baseando-se mais nos aspectos plásticos (estéticos) do que na similaridade com o edifício que irão projetar;

(ii) $O$ professor seleciona o projeto de referência: projetos escolhidos pelos professores, cuidadosamente: projetos que receberam boa crítica ou desenvolvidos por arquiteto ou escritório reconhecido nacional ou internacionalmente ou que receberam grande divulgação, etc., ou seja, projetos considerados de "qualidade", entretanto as análises acabam sendo superficiais (mais uma vez, baseadas apenas nos aspectos plásticos) e a atividade, "esvaziada", não fornece subsídios e conteúdo para o projeto que se vai desenvolver; (iii) A análise de referências para ser realizada fora sala de aula: como "tarefa para casa", os alunos não demonstram interesse na atividade e nem se dedicam às reflexões necessárias. Entregam, recebem nota (na maior parte das vezes a atividade tem peso muito pequeno na nota do semestre), não recebem devolutiva, dificilmente a utilizam como subsidio e conteúdo para o projeto e a atividade fica, mais uma vez, "esvaziada"; (iv) A análise de referência, desenvolvida sob critérios claros de análise, fornecidos pelos professores: os estudantes realizam a atividade fora da sala de aula e, mesmo com os critérios fornecidos, mapeiam os aspectos visivelmente mais para "cumprir" a tarefa solicitada do que para refletir. A atividade resulta em "perda de tempo", uma vez que não agrega conhecimento para o desenvolvimento do projeto futuro;

(v) A análise de referência, com apresentação em sala, ao grande grupo: os estudantes realizam a atividade fora da sala de aula, muitas vezes em equipe e apresentam os resultados para a turma, utilizando slides (PowerPoint). Além de análises superficiais, na maior parte das vezes a turma não se interessa pela apresentação dos colegas, dispendendo esforços e atenção apenas para as suas próprias referências. Não havendo interesse na atividade, a devolutiva dos professores acaba sendo superficial e apressada;

(vi) A análise de referência apresentada em pranchas: realizada em equipes, o resultado é apresentado em prancha plotada (formato A3 ou A2), algumas vezes fixada nas paredes da sala de aula para que toda a turma possa analisar. Neste caso, as variações consistem em o professor fazer uma devolutiva geral ou pedir para que os alunos primeiro apresentem (apresentação oral) para todos para, depois, fazer uma devolutiva geral. Mais uma vez reduzida, na visão do estudante, a apenas mais uma "tarefa a ser cumprida", na maior parte das vezes esta atividade não apresenta resultados significativos apesar de sua importância para o ensino-aprendizagem de projeto. 
É para pessoas que estão envolvidas no desafio de praticar a arquitetura, não apenas de olhar para ela. O objetivo é tentar entender como a arquitetura funciona e o que ela pode fazer (...) este método analisa produtos de arquitetura de modo a expor os processos intelectuais que os fundamentam (UNWIN, 2013, p.01).

Para a turma na qual foi aplicada a experiência do projeto piloto, decidiu-se pela seguinte abordagem:

1. Os alunos selecionavam o projeto a ser analisado. Os critérios específicos para a busca e seleção de tal projeto era que ele tivesse sido elaborado por arquitetos, ou escritórios de arquitetura, incluídos na relação do prêmio Pritzker ${ }^{6}$. Desta forma, imaginou-se maximizar as possibilidades de conseguir exemplos significativos;

2. Só seriam aceitos projetos similares em uso (uma escola de Ensino Fundamental) e porte (metragem quadrada) ao projeto que iriam desenvolver. Se o projeto de referência fosse um exemplo de fora do Brasil, ele deveria ser de uma escola para a mesma faixa etária do ensino fundamental no país, ou seja, para estudantes entre 5 a 14 anos;

3. Os estudantes deveriam buscar e selecionar três projetos. O objetivo era o de que, durante a busca, viessem a conhecer vários projetos de forma a ampliar o repertório arquitetônico pessoal;

4. Os projetos selecionados deveriam ter material gráfico suficiente para a perfeita realização da atividade e apresentar, pelo menos, as seguintes peças gráficas: implantação, planta de todos os pavimentos, pelo menos 1 corte e 1 elevação. Os estudantes deveriam também trazer algumas imagens externas e internas do edifício;

5. Os três exemplos seriam trazidos em cópia simples, formato A4. Em sala, os professores selecionariam apenas um dentre eles, e o critério seria a similaridade de uso e porte, qualidade das peças gráficas, pertinência dos projetos para as competências pretendidas na atividade. Após a seleção do projeto, cada integrante da equipe deveria fazer cópia do jogo completo das peças gráficas e imagens.

Como metodologia ativa, a atividade descrita acima pode ser descrita como Sala de Aula Invertida ou flipped classroom que, numa definição simplificada, é um "método de ensino em que o professor aproveita o momento em sala de aula para fazer atividades que aplicam conceitos previamente apresentados no ambiente virtual de aprendizagem, por meio de vídeos ou leituras orientadas" (material fornecido pelo CreARe e disponibilizado nas oficinas de atualização docente).

Como se pode perceber, nos itens descritos acima, a atividade de busca e seleção de projetos de referência, desenvolvida fora de sala de aula, apresenta as características desta metodologia. Apesar de o professor não ter "fornecido o material de estudo" (os projetos de referência) e do material não estar relacionado a "vídeo ou texto" diretamente, a atividade realizada fora da sala de aula foi uma preparação para o conteúdo a ser abordado e trabalhado em sala de aula.

6. Em sala, a aula iniciaria com uma explicação prévia do porquê da atividade e do que se pretendia alcançar, em termos de resultados de aprendizagem e competências, com o desenvolvimento dela;

7. A atividade seria desenvolvida integralmente em sala de aula;

8. A atividade seria desenvolvida em grupo. O objetivo era a construção coletiva (diferentes "olhares") do conhecimento. As equipes foram formadas pelo professor com integrantes escolhidos de forma "aleatória", a partir da lista de chamada e evitar "os mesmos grupos de sempre". A mesma equipe seria mantida até o final da atividade;

9. A análise da referência seria desenvolvida em "partes" e, para tanto, os professores dividiriam o conteúdo em tópicos a serem abordados um a um, em separado. A atividade consistia em encontrar no projeto a ser analisado cada um dos "elementos" (tópicos) abaixo relacionados; uma vez encontrado, os estudantes deveriam mapeá-lo (registrá-lo graficamente) isoladamente e analisa-lo em relação a outros da listagem abaixo, levantando hipóteses do porquê da escolha feita pelo(s) arquiteto(s).

Apesar de existirem muitos aspectos a serem abordados decidiu-se, nesta primeira experiência, começar com apenas tópicos mais gerais de análise. Se a atividade tivesse bons resultados, mais aspectos seriam incluídos numa próxima oportunidade. Estes aspectos foram divididos em "O Local" e "O Edifício", conforme descrito abaixo:

O Local - utilizando a cópia da prancha de implantação do projeto selecionado e as informações do entorno, obtidas pelo Google Maps e Street View, os estudantes deveriam buscar e mapear:

- Massa da área construída X massa da área não construída e suas relações;

- Levantar as possíveis "interferências" existentes no entorno que poderiam ter influenciado na definição da implantação do edifício no local;

- Levantar os acessos principais (pedestre e veículos) ao terreno e levantar hipóteses do porquê da escolha (rua mais movimentada, rua com melhor visualização do edifício, rua com maior fluxo de pedestres e de veículos, etc.);

- Marcar a orientação solar e analisar quais setores/ambientes do edifício estariam posicionados para qual orientação; 
- Marcar os principais visuais a partir da rua para o terreno (obtidos através do Street View).

O Edifício - utilizando a cópia das pranchas das plantas, cortes, elevações e as imagens externas e internas do edifício, os estudantes deveriam buscar e mapear:

- Marcar os acessos principais (pedestre e veículos) ao edifício e a relação deles com os setores/ambientes posicionados diretamente em frente a eles ou não, etc.;

- Mapear os diferentes setores do edifício (por exemplo: setor didático, setor administrativo e assim por diante);

- Mapear os fluxos. Antes, definir os diversos usuários (tais como funcionários, visitantes, etc.) que poderiam utilizar os diferentes acessos;

- Mapear eixos/modulação existentes. Análise de possíveis modulações, eixos de estrutura ou de formatação dos espaços;

- Volumetria e materiais de acabamento. Em perspectiva "livre", representar a relação volumétrica das "partes" do edifício. Relacionar, por escrito, os diferentes materiais utilizados e tentar entender o porquê das escolhas.

10. Os estudantes deveriam primeiro discutir e refletir, em grupo, sobre cada tópico para, posteriormente, desenvolver os "exercícios" de mapeamento gráfico, de forma individual. A figura 1, abaixo, mostra esta dinâmica sendo realizada em sala;

Figura 1: Trabalho em sala, em grupo de 4 a 5 alunos.

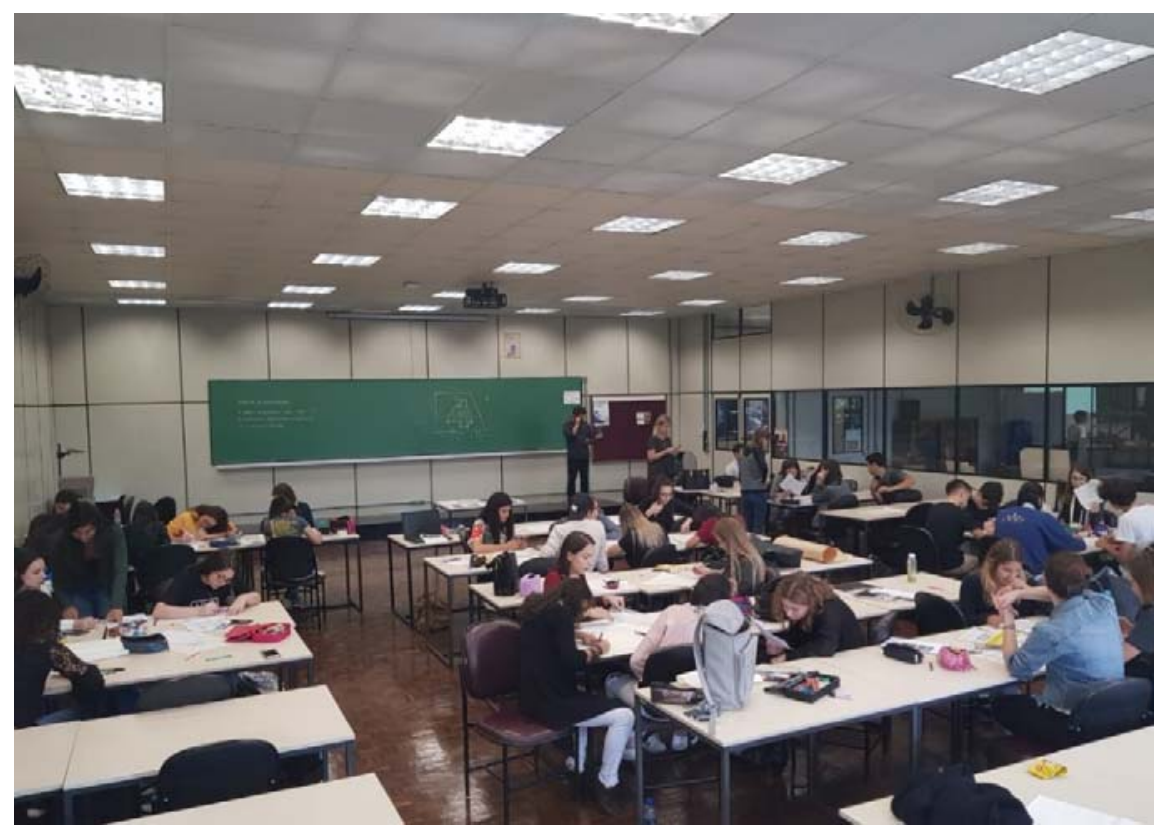

Fonte: Acervo próprio.

11. O "mapeamento" seria representado por diagramas, esquemas, croquis, etc., usando marcadores e/ou lápis de cor, em pranchas de papel sulfurize ou papel manteiga, formato A3, sobre a cópia das peças gráficas do projeto selecionado. O espaço que sobraria nas pranchas seria utilizado para anotações, ensaios e reflexões a respeito de cada item levantado;

12. Os professores conduziriam a atividade apresentando, um a um, cada tópico a ser analisado e estipulando tempo suficiente para o seu desenvolvimento. Após uma breve exposição do tópico, com explicações e apresentação de exemplos práticos, os alunos deveriam iniciar as atividades;

13. A representação era livre, mas o desenho precisava ser expressivo e comunicativo;

14. Individualmente, também, os estudantes deveriam escrever pequenos textos (com 3 linhas no máximo) que apresentassem as hipóteses levantadas na reflexão em grupo, do porquê da escolha do arquiteto.

Como metodologia ativa, as atividades apresentadas acima podem ser descritas como Estudo de Caso que, numa definição simplificada é

o método de ensino em que o professor apresenta situações-problema em sala de aula, em contextos com ambiguidade e que possibilitam mais de uma solução. O professor media a discussão utilizando aspectos apresentados no texto que apresenta a problematização. É apropriadamente desafiador para o público alvo e integra conceitos múltiplos, sendo aberto a múltiplas soluções ou caminhos para buscar soluções, dependendo das hipóteses dos estudantes e de argumentação razoável. Pode ser encaminhado previamente no ambiente 
virtual de aprendizagem com alguma questão norteadora e materiais de apoio, se assim o docente julgar necessário (Material fornecido pelo CreARe e disponibilizado nas oficinas de atualização docente).

\section{Outra definição descreve Estudo de Caso como}

(...) uma abordagem de ensino baseada em situações de contexto real. As abordagens de ensino e aprendizagem baseadas em situações de contexto real são poderosas para desenvolver competências e habilidades relativas à resolução de problemas, à tomada de decisão, à capacidade de argumentação e ao trabalho efetivo em equipe. O estudo de caso tem o potencial de trazer ao contexto real conceitos que podem ser abstratos ou desconexos, caso sejam abordados apenas teoricamente e isoladamente. Pressupõe a participação ativa do estudante na resolução de questões relativas ao caso, normalmente em um ambiente colaborativo com seus pares. Apesar de poder ser resolvido individualmente, uma das maiores riquezas dessa abordagem de ensino é a interação pedagógica que promove mudanças significativas na sala de aula. Trata-se de uma abordagem ativa e colaborativa, que promove o desenvolvimento da autonomia e da metacognição, quando conduzido de forma apropriada. Os casos são construídos em torno de objetivos de aprendizagem (habilidades e competências) que se pretende desenvolver, e são seguidos de questões que devem ser respondidas pelos estudantes. A presença dessas questões torna o estudo de caso uma abordagem de ensino guiada. Os estudantes analisam os saberes necessários para a resolução do caso, pesquisam e discutem em pequenos grupos (SPRICIGO, 2014, p.01).

As análises de referências desenvolvidas em sala de aula, consideradas "situação problema, em contextos de ambiguidade e sem uma única resposta como solução", são estudos de casos, na medida em que o professor circula pelas mesas dos grupos e levanta hipóteses e, ao fazer perguntas relacionadas ao conteúdo, além de apresentar quais aspectos devem ser analisados e o porquê de analisa-los, "media a discussão". Além disto, esta atividade certamente "integra conceitos múltiplos, sendo aberto a múltiplas soluções ou caminhos para tal", como o é, de fato, um projeto de arquitetura. No estudo de caso destaca-se a importância do trabalho efetivo em grupo e, a forma como a turma trabalhou durante toda a atividade se mostrou como um dos pontos fortes da metodologia. Refletindo em conjunto, os estudantes ganham com as descobertas que surgem a partir dos diferentes "olhares" ao mesmo problema.

15. Ao final, os estudantes entregariam um portfolio do material produzido, contendo as análises realizadas em sala e revisadas e organizadas em casa. O portfolio receberia avaliação formativa, ou seja, não valeria nota;

16. Na aula em que o portfolio seria entregue, os grupos se juntariam, dois a dois, para apresentar um para o outro (vale lembrar que cada equipe realizou a análise de um projeto distinto). Esperava-se que ao apresentar o resultado da análise, os grupos refletissem mais uma vez sobre o que desenvolveram, ao mesmo tempo em que teriam a oportunidade de conhecer a análise de um novo projeto;

17. Foi solicitado um "relatório", escrito pelos dois grupos em conjunto, destacando as similaridades e as diferenças encontradas em cada um dos projetos, em relação aos tópicos analisados;

18. Repetiu-se , uma outra vez, a dinâmica de apresentação entre grupos, ou seja, cada grupo analisou um projeto e conheceu outros dois, trabalhados pelos demais grupos;

Figura 2: Feedback de encerramento da atividade, em grande grupo.

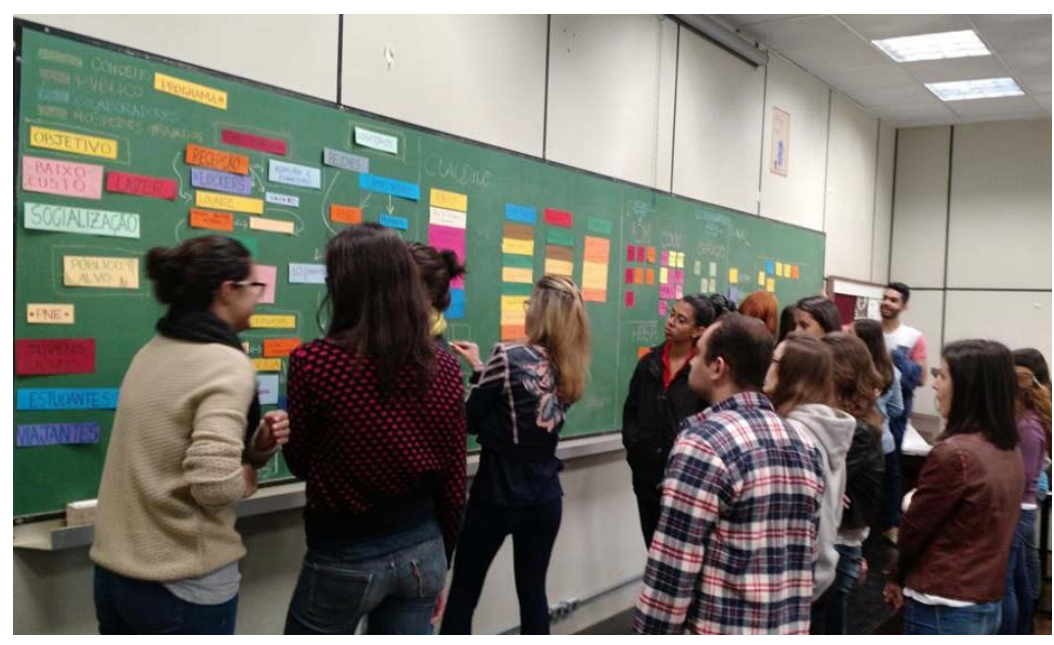

Fonte: Acervo próprio. 
19. A atividade foi finalizada com um feedback em grande grupo, conforme apresentado na figura 2 acima, onde discutiuse questões gerais analisadas e mapeadas e tentou-se encontrar pontos em comum, questões recorrentes, entre os projetos. Foram recolhidos os portfolios para avaliação posterior do professor quanto ao alcance da atividade.

\section{CONCLUSÃo}

A experiência apresentada, desenvolvida a partir do Projeto Piloto de Inovação no Ensino da PUCPR, proporcionou uma oportunidade de testar mudanças significativas na disciplina de Projeto de Arquitetura IV, do terceiro ano do curso de Arquitetura e Urbanismo da PUCPR.

Ajustou-se o cronograma de forma a poder praticar, de forma clara e definida, a etapa inicial do "processo de projeto" e só depois partir para o desenvolvimento do Estudo Preliminar (conforme previsto na NBR 13532, "Elaboração de projetos de edificações - Arquitetura"). No desenvolvimento da experiência foi possível utilizar diversas estratégias de aprendizagem ativa e de aplicar uma "nova" (em comparação ao que se costumava fazer) forma de desenvolver a atividade de Análise de Referências, objeto deste estudo.

Como pontos positivos, pode-se destacar que as atividades foram realizadas totalmente em sala de aula, aspecto de grande importância não só porque a sala de aula é o ambiente da troca e da reflexão conjunta, e onde o professor está disponível para ajudar a pensar na resolução dos problemas, mas também porque desenvolver o trabalho em sala reduz o conhecido "excesso de tarefas de casa" que os alunos de arquitetura costumam ter. Nesta experiência, aproximadamente $85 \%$ dos alunos realizou as atividades integralmente em sala.

Outro aspecto importante é que o trabalho realizado em grupo permite que os estudantes socializem suas análises, reflexões e descobertas com os demais colegas, aprimorando desta forma a aprendizagem ao mesmo tempo em que desenvolvem habilidades de trabalho colaborativo. Em pouco tempo, aproximadamente duas semanas, foi possível perceber que as discussões estavam mais maduras e que 0 envolvimento, motivação e participação dos estudantes aumentou muito. Ao apresentar as análises realizadas para os demais grupos, os estudantes defendiam as qualidades dos projetos de referência como se eles próprios os tivessem elaborado.

Ficou também evidente a importância do feedback constante e imediato, visando à aprendizagem efetiva. Após o término de cada atividade, só se iniciava a próxima após realizar um feedback em grande grupo, oportunidade em que os alunos traziam as questões que cada grupo tratou de forma diferente e elas eram discutidas em conjunto.

O uso de metodologias ativas ajudou no engajamento do desenvolvimento das atividades. Em pouco tempo, os grupos pareciam não mais aguardar a chegada do professor na mesa de trabalho e davam prosseguimento às atividades de forma autônoma, demonstrando mais responsabilidade pela própria aprendizagem e pela aprendizagem dos colegas.

É bom ressaltar que alguns pontos precisam de atenção contínua, como por exemplo: em grande parte das metodologias ativas é fundamental a discussão e a reflexão em conjunto. Deve-se, portanto, ficar atento se isto está de fato acontecendo. Para tanto, o professor deve circular pelas equipes o tempo todo incitando o contínuo debate e o levantamento de hipóteses possíveis para o problema a ser analisado. Como mediador na construção do conhecimento, o professor não deve apresentar respostas prontas, mas sim motivar os estudantes a refletir e a pesquisar. Uma estratégia interessante é responder com novas perguntas dando indicação de como e onde devem buscar mais informações para conseguir, de forma autônoma, a resposta.

É importante, também, pré-estipular e controlar o tempo para o desenvolvimento de cada atividade de forma a evitar dispersão ou perda de interesse por parte dos alunos. Este controle também ajuda os estudantes a gerenciar seu próprio tempo, e o tempo do grupo, na execução das atividades.

O registro da experiência se deu por meio da observação direta da aplicação da experiência, aula a aula. Também utilizou as observações levantadas a partir de conversas informais com os alunos e a imediata anotação, por parte do professor, das impressões coletadas em um Diário de Bordo, de forma a realizar uma análise futura. As atividades realizadas na disciplina e entregues no final do semestre construíram o acervo da experiência e possibilitaram medir os resultados de aprendizagem alcançados. Todo este material em conjunto gerou de dados a partir dos quais foram derivados os resultados do presente estudo. 
BEHRENS, M. A. O paradigma emergente e a prática pedagógica. Ed. Petrópolis: Vozes. 2011.

CHING, F.D.K. Arquitetura de interiores. São Paulo: Ed. Artmed, 2006.

CAMARGO, F.; DAROS, T. A sala de aula inovadora: estratégias pedagógicas para fomentar o aprendizado ativo. Porto Alegre: Ed. Penso, 2018.

CORDIVIOLA, A. R. Notas sobre o saber projetar. Arquitextos, Texto Especial n 103. São Paulo, Portal Vitruvius, outubro 2001. Disponível em http://www.vitruvius.com.br/arquitextos/arq000/esp103.asp. Acesso em 20 de fevereiro de 2019.

LARA, F. L.; MARQUES, S. O projeto do projeto. Arquitextos, São Paulo, ano 04, n. 045.00, Vitruvius, fev. 2004. Disponível em: http://www.vitruvius.com.br/revistas/read/arquitextos/04.045/604. Acesso em 20 de fevereiro de 2019.

MARTINEZ, A. C. Ensaio sobre o projeto. Brasília: Ed. da UnB, 2000.

NEVES, L.P. Adoção do partido na arquitetura. Salvador: Ed. Da UFBA, 1998.

PIÑON, H. Teoria do Projeto. Porto Alegre: Ed.Livraria do Arquiteto, 2007.

RUFINONI, M.R. Novos e velhos desafios no ensino de projeto arquitetônico: caminhos para a formação de uma consciência crítica. Revista Sinergia (CEFETSP), São Paulo, v. 04, n.1, jan. 2002.

SILVA, E. Uma introdução ao projeto arquitetônico. Porto Alegre: Ed. da UFRGS, 2006.

SPRICIGO, B. C.; MANFFRA, F. E.; SAROYAN, A. A course design workshop as a possible path from a content-centered to a learning-centered teaching. Revista Diálogo Educacional. Curitiba, v. 17, n. 52, abr./jun. 2017 PUCPR. Disponível em http://dx.doi.org/10.7213/1981-416X.17.052.DS02. Acesso em 14 de março de 2019.

SPRICIGO, B.C. Estudo de caso como abordagem de ensino. PUCPR. Disponível em https://www.pucpr.br/wpcontent/uploads/2017/10/estudo-de-caso-como-abordagem-de-ensino.pdf. Acesso em 14 de março de 2019.

UNWIN, S. A análise da Arquitetura. Porto Alegre: Bookman, 2013.

\section{NOTAS}

${ }^{1}$ Disciplina responsável por ensinar e praticar a elaboração e o desenvolvimento de projetos de arquitetura e que, dependendo da escola, apresenta nomes diferentes.

${ }^{2}$ As discussões mais sistematizadas acerca deste assunto são relativamente recentes: na década de 80 aconteceram iniciativas interessantes de discussão dessa temática em encontros, seminários e publicações organizados pela ABEA (Associação Brasileira de Ensino de Arquitetura) e também o encontro sobre o Ensino de Projeto Arquitetônico, realizado na Faculdade de Arquitetura da Universidade Federal do Rio Grande do Sul (UFRGS). Procurava-se, naquela época, "discutir o aprimoramento da formação do arquiteto, o que envolvia necessariamente o aprimoramento do ensino do projeto arquitetônico" (LARA E MARQUES, 2004). A partir de 2003, com a primeira edição do Seminário Projetar - evento científico que reuniu profissionais e professores de Arquitetura e Urbanismo, brasileiros e estrangeiros, para debater o ensino de Projeto - começou a surgir uma discussão mais sistematizada sobre este tema. Edições bienais do Seminário - considerado o maior fórum brasileiro voltado para a pesquisa, ensino e prática de projeto de arquitetura e urbanismo e que enfoca o projeto como instrumento para a materialização da arquitetura - continuam a ocorrer, sendo que a última, a oitava edição, ocorreu em novembro de 2017, em Buenos Aires, na Argentina. Em decorrência destes encontros, um número crescente de artigos, dissertações e teses de pesquisadores de várias instituições de ensino superior, vem sendo produzido, além de iniciativas de aplicação de diferentes metodologias de ensino estarem sendo praticadas nas escolas do país, demonstrando que atualmente a discussão ganha espaços sem precedentes na história do ensino de projeto no Brasil.

${ }^{3}$ O Projeto Pedagógico do curso (PPC, 2013) prevê, como pré-requisito para esta disciplina, as seguintes disciplinas: Projeto de Arquitetura I, II e III, respectivamente do $3^{\circ}, 4^{\circ}$. e $5^{\circ}$ períodos do curso. Esta disciplina promove conhecimentos e habilidades para o bom desenvolvimento das demais disciplinas de projeto do curso: Projeto de Arquitetura V, VI e Atelier Integrado, do $7^{\circ}, 8^{\circ}$ e $9^{\circ}$ períodos e o Trabalho Final de Graduação/TFG, do $10^{\circ}$ período. Ementa: "Estudo histórico e conceitual de temas arquitetônicos, suas tipologias, tendências e referências. Leitura, análise e interpretação de espaços urbanos ou naturais e definição de diretrizes para fins de intervenção e transformação. Elaboração, desenvolvimento e representação de projetos arquitetônicos de médio porte e complexidade como resposta contemporânea às necessidades sociais, ambientais e técnicas do lugar. Projetos permanentes ou efêmeros. Execução de instalações permanentes ou efêmeras. Elaboração de memorial descritivo. Coordenação e compatibilização de projetos. Pesquisa aplicada e controle de qualidade de projeto".

4 De certa forma, no desenvolvimento do Trabalho Final de Graduação é exigido, ou esperado, que os estudantes desenvolvam seus projetos da forma como a norma prevê, mas uma vez que este conteúdo não é regularmente abordado no curso de graduação, os estudantes, por não terem desenvolvido ou refletido previamente a respeito destas etapas iniciais, sentem e demonstram enorme dificuldade em desenvolvê-las. 
$51^{\circ}$.: maior reflexão do significado do tipo (uso) do edifício: O que é uma escola? O que as pessoas entendem e esperam de uma escola? Quais são as expectativas dos usuários principais, os alunos, em relação a uma escola? E dos pais desses alunos? E dos professores ou da comunidade onde ela está inserida? $2^{\circ} .:$ realizar o que se chama de Análise de Referências, onde os alunos devem pesquisar e selecionar, dentre inúmeros projetos já realizados e disponíveis em publicações impressas em livros ou revistas, ou divulgados em websites de arquitetura, três exemplos de projetos (referências) similares em uso, metragem quadrada, etc., ao projeto que irão desenvolver. $3^{\circ}$. : o Briefing com o cliente e sua importância para o projeto: como fazer? o que e como perguntar ao cliente, etc. $4^{\circ} .:$ o Conceito em projetos de arquitetura: diferentes abordagens, a importância do conceito para o processo de projetação, como um todo, etc. $5^{\circ}$.: o Programa de Necessidades: importância, como fazer, como organizar as informações coletadas, como tratar estas informações, etc. $6^{\circ} .:$ o Pré-Dimensionamento dos ambientes relacionados no programa de necessidades. $7^{\circ} .:$ Legislação, importância de um levantamento abrangente e uma cuidadosa análise da legislação local. $8^{\circ} .:$ a Análise do Terreno e do seu entorno imediato. $9^{\circ} .:$ Legislação de Uso de Solo, levantamento, análise e interpretação. $10^{\circ} .:$ o Partido em projetos de arquitetura e o que se chama de Estratégia de Implantação, ou seja, os primeiros estudos, croquis, sketchs do projeto, através de manchas, bolhas, etc.

6 "The Pritzker Architecture Prize. The purpose is to honor a living architect or architects whose built work demonstrates a combination of those qualities of talent, vision, and commitment, which has produced consistent and significant contributions to humanity and the built environment through the art of architecture. The international prize, which is awarded each year to a living architect/s for significant achievement, was established by the Pritzker family of Chicago through their Hyatt Foundation in 1979. It is granted annually and is often referred to as "architecture's Nobel" and "the profession's highest honor", disponível em https://www.pritzkerprize.com, Acesso em 02 de abril de 2019.

NOTA DO EDITOR (*) O conteúdo do artigo e as imagens nele publicadas são de responsabilidade do(s) autor(es). 